\title{
Primary pulmonary lymphoepithelioma-like carcinoma initially diagnosed as squamous metaplasia: A case report and literature review
}

\author{
YASHA LIANG ${ }^{1}$, CHENG SHEN $^{2}$, GUOWEI CHE $^{2}$ and FENGMING LUO ${ }^{1}$ \\ Departments of ${ }^{1}$ General Practice, and ${ }^{2}$ Cardiovascular and Thoracic Surgery, West-China Hospital, Sichuan University, \\ Chengdu, Sichuan 610041, P.R. China
}

Received March 30, 2014; Accepted December 19, 2014

DOI: $10.3892 / \mathrm{ol} .2015 .2975$

\begin{abstract}
A mass was detected in the middle lobe of the right lung of a 58-year-old female. The patient did not present any symptoms and was a nonsmoker. Diagnostic evaluation revealed squamous metaplasia in the middle lobe of the right lung. During surgery, a tumor was identified, which was diagnosed as a lymphoepithelioma-like carcinoma (LELC). LELCs have been mainly reported in the Asian population and are associated with the Epstein-Barr virus (EBVs), while they are not associated with smoking. Squamous metaplasia, which is the basis of squamous cell carcinoma, differs from LELC in the therapeutic methods used and the prognostic evaluation. Squamous metaplasia requires regular follow-up in out-patient clinics, while pulmonary LELC is treated by surgery and chemotherapy. Therefore, distinguishing between LELCs and other nonmalignant or premalignant conditions is essential.
\end{abstract}

\section{Introduction}

Lymphoepithelial carcinoma is a nasopharyngeal carcinoma with lymphoid stroma and nonkeratinizing squamous cells. Lymphoepithelioma-like carcinomas (LELCs) arise on the exterior of the nasopharynx; however, they resemble lymphoepithelial carcinomas histologically. LELCs commonly occur close to the nasopharynx, while they have also been detected in other sites, including the salivary glands (1), lungs (2-4), skin (5), liver, cervix, urinary bladder (6), breast (7), thymus and stomach (8). Certain LELC types are associated with Epstein-Barr virus (EBV) infection (particularly LELCs of the stomach, salivary glands, lungs, skin and thymus) $(4,5,9)$. Pulmonary LELCs are rare malignancies, usually detected in nonsmokers (10-13). A total of 9,851 patients with NSCLC were

Correspondence to: Professor Fengming Luo, Department of General Practice, West-China Hospital, Sichuan University, 37 Guo Xue Xiang, Chengdu, Sichuan 610041, P.R. China

E-mail: luofengming_hx@sina.com

Key words: lymphoepithelioma-like carcinoma, pulmonary identified. Among these patients, 37 (0.4\%) were diagnosed with lung LELC. These 37 patients were all from Southern China (14). Chang et al (11) estimated that pulmonary LELC represents $\sim 0.92 \%$ of all lung cancers, further illustrating the rarity of pulmonary LELCs. Primary pulmonary LELC exhibits no significant gender predisposition and a minimal association with smoking history, however, it exhibits a strong association with EBV in Asian populations, and a predisposition for early or locally advanced stages of the disease. In a previous study, the mean age of patients with lung LELC was reported to be 10 years younger than that of patients with other histological types of lung carcinoma (14). Currently, the youngest pulmonary LELC patient reported in the literature is an eight-year-old child (15). The majority of patients undergo complete resection, as well as chemotherapy and radiotherapy for the treatment of pulmonary LELC. Recently, a study of 52 primary pulmonary LELC patients demonstrated that the two- and five-year overall survival rates were 88 and $62 \%$, respectively, with the majority of patients diagnosed at early or locally advanced stages of the disease (16). The present study investigated the case of a female nonsmoker with pulmonary LELC. Written informed consent was obtained from the patient.

\section{Case report}

A mass was detected on the middle lobe of the right lung of a 58-year-old female, during a medical check-up at the West-China Hospital (Chengdu, China) in January 2013. The patient was asymptomatic and physical examination identified no positive findings. The female had no history of smoking and alcohol use.

Enhancement computed tomography (CT) of the thorax revealed a mass in the middle lobe of the right lung, which was considered to be a possible lung tumor (Fig. 1). In addition, another small lesion was detected in the same lung lobe; however, this was not considered to be a metastatic lesion. Fibrobronchoscopic brushing (17) demonstrated the presence of squamous metaplasia with severe hyperplasia at the middle lobe of the right lung. A bone scan and a CT scan of the skull indicated no metastasis.

Surgery was performed under induction with midazolam (0.05-0.1 $\mathrm{mg} / \mathrm{kg})$ followed by the subsequent use of 

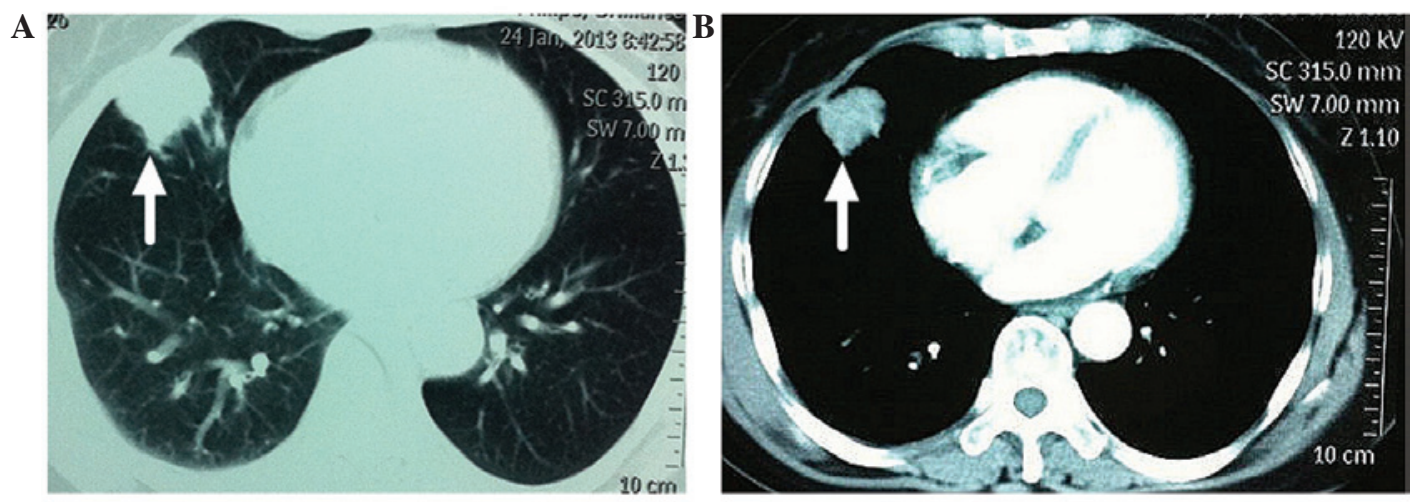

Figure 1. Computed tomography (CT) scans revealing a tissue mass. Enhancement thoracic CT demonstrated a mass in (A) the middle lobe of the right lung and the (B) mediastinum window, which was a possible lung tumor.
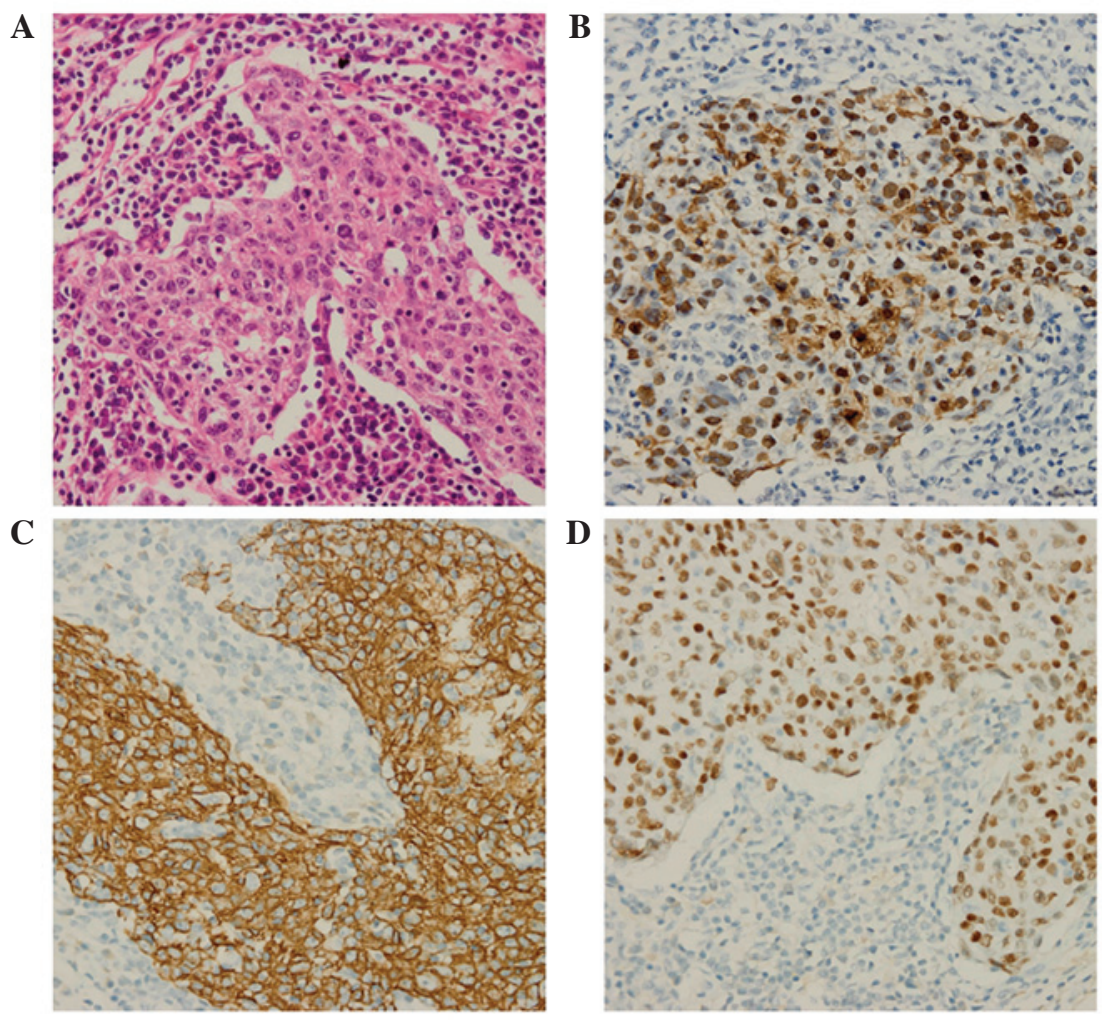

Figure 2. Histological features of lymphoepithelioma-like carcinoma of the lung. (A) Histological examination revealed a large island of tumor cells infiltrated by intense lymphoplasmacytic cell population (HE; magnification, x400). (B) Cells were positive for Epstein-Barr virus (EBV)-encoded small nonpolyadenylated RNA (magnification, $\mathrm{x} 400$ ). Immunohistochemical staining revealed that the specimen cells were positive for (C) cytokeratin 5/6 (magnification, 400x) and (D) P63 (magnification, x400). HE, hematoxylin and eosin.

intravenous anesthesia $(2 \mu \mathrm{g} / \mathrm{kg}$, sufentanil; $2 \mathrm{mg} / \mathrm{kg} / \mathrm{h}$, propofol) with tracheal intubation. The patient underwent a lobectomy of the middle lobe (including sequential resection of the right pulmonary middle lobe vein, artery and trachea) and systematic mediastinal lymphadenectomy (group 2-4, 7 and 9-11 lymph nodes were swollen). The resected tissue and lymph nodes were frozen and biopsy was performed, revealing evidence of carcinoma. The surgery was completed following careful hemostasis and washing of the pleural cavity with warm saline solution. The patient did not present any complications, such as cough, chest pain and hemoptysis. No adjuvant chemotherapy and radiotherapy were performed. The patient was discharged a week after surgery and follow-up visits were scheduled. The resected specimen was $10 \times 5 \times 3 \mathrm{~cm}$ in size, containing a $3 \times 2.5 \times 2 \mathrm{~cm}$ tumor. Histologically, the tumor was solid and off-white in color, with a clear demarcation between the surrounding normal lung tissues, while pleural invasion was observed. Immunohistochemical analysis revealed that the tumor cells were positive for protein kinase C, p63, cytokeratin 5/6 (CK 5/6) and EBV-encoded small RNA (EBER), whereas the cells were negative for CK 7 and thyroid transcription factor-1 (Fig. 2). Lymph nodes collected during the surgery revealed no metastasis. Furthermore, the histological and 
Table I. Patient characteristics of the 196 cases of pulmonary lymphoepithelioma-like carcinoma published between 1987 and 2015 in the English literature.

\begin{tabular}{|c|c|c|c|c|}
\hline $\begin{array}{l}\text { Author, year } \\
\text { (ref) }\end{array}$ & $\begin{array}{l}\text { Cases, n } \\
\text { (F/M) }\end{array}$ & $\begin{array}{c}\text { Age } \\
\text { (years) }\end{array}$ & $\begin{array}{c}\text { Smoking status, } \mathrm{n} \\
(\mathrm{S} / \mathrm{NS})\end{array}$ & $\begin{array}{c}\text { EBV, n } \\
(+/-)\end{array}$ \\
\hline Ma et al, 2013 (19) & $41(19 / 22)$ & $25-74^{\mathrm{a}}$ & $10 / 31$ & $37 / 4$ \\
\hline Jeong et al, 2013 (21) & $1(1 / 0)$ & 60 & $0 / 1$ & $1 / 0$ \\
\hline Dong et al, 2015 (22) & $1(0 / 1)$ & 83 & $\mathrm{~N} / \mathrm{A}$ & $\mathrm{N} / \mathrm{A}$ \\
\hline Yener et al, 2012 (23) & $1(0 / 1)$ & 62 & $1 / 0$ & $0 / 1$ \\
\hline Tanaka et al, 2012 (24) & $1(1 / 0)$ & 71 & $0 / 1$ & $0 / 1$ \\
\hline Shen et al, 2012 (25) & $1(1 / 0)$ & 75 & $1 / 0$ & $1 / 0$ \\
\hline Hayashi et al, 2012 (20) & $1(0 / 1)$ & 70 & $0 / 1$ & $1 / 0$ \\
\hline Xia et al, 2009 (26) & $21(8 / 13)$ & $40-67^{a}$ & $7 / 14$ & $12 / 9$ \\
\hline Bildirici et al, 2005 (27) & $1(1 / 0)$ & 66 & $0 / 1$ & $0 / 1$ \\
\hline Ngan et al, 2004 (18) & $19(10 / 9)$ & $52.7^{\mathrm{b}}$ & $8 / 11$ & $11 / 8$ \\
\hline Kobayashi et al, 2004 (28) & $1(1 / 0)$ & 67 & $\mathrm{~N} / \mathrm{A}$ & $1 / 0$ \\
\hline Ho et al, 2004 (29) & $10(5 / 5)$ & $38-71^{\mathrm{a}}$ & $2 / 8$ & $6 / 4$ \\
\hline Hernández Vázquez, et al 2004 (30) & $1(0 / 1)$ & 59 & $1 / 0$ & $\mathrm{~N} / \mathrm{A}$ \\
\hline Abe et al, 2004 (31) & $1(1 / 0)$ & 57 & $0 / 1$ & $\mathrm{~N} / \mathrm{A}$ \\
\hline Morbini et al, 2003 (32) & $1(0 / 1)$ & 25 & $0 / 1$ & $1 / 0$ \\
\hline Chang et al, 2002 (11) & $23(16 / 7)$ & $42-80^{\mathrm{a}}$ & $6 / 17$ & $23 / 0$ \\
\hline Han et al, 2001 (12) & $32(10 / 22)$ & $39-73^{a}$ & $\mathrm{~N} / \mathrm{A}$ & $30 / 2$ \\
\hline Barroso et al, 2000 (33) & $1(0 / 1)$ & 25 & $0 / 1$ & $1 / 0$ \\
\hline Kasai et al, 1999 (34) & $1(1 / 0)$ & 39 & $1 / 0$ & $1 / 0$ \\
\hline Chen et al, 1998 (14) & $5(3 / 2)$ & $43-66^{\mathrm{a}}$ & $0 / 5$ & $5 / 0$ \\
\hline Wöckel et al, 1997 (35) & $2(1 / 1)$ & 49,66 & $\mathrm{~N} / \mathrm{A}$ & $\mathrm{N} / \mathrm{A}$ \\
\hline Curcio et al, 1997 (15) & $1(1 / 0)$ & 8 & $0 / 1$ & $1 / 0$ \\
\hline Wong et al, 1995 (36) & $9(1 / 8)$ & $33-71^{\mathrm{a}}$ & $4 / 5$ & $9 / 0$ \\
\hline Wöckel et al, 1995 (37) & $1(1 / 0)$ & 47 & $0 / 1$ & NA \\
\hline Higashiyama et al, 1995 (9) & $2(0 / 2)$ & 55,65 & N/A & $2 / 0$ \\
\hline Ferrara and Nappi, 1995 (2) & $2(1 / 1)$ & 64,78 & $1 / 1$ & $0 / 2$ \\
\hline Chow et al, 1995 (38) & $2(0 / 2)$ & 56,66 & $\mathrm{~N} / \mathrm{A}$ & $\mathrm{N} / \mathrm{A}$ \\
\hline Chan et al, 1995 (3) & $11(5 / 6)$ & $38-73^{a}$ & $2 / 9$ & $11 / 0$ \\
\hline Miller et al, 1991 (39) & $1(1 / 0)$ & 65 & $1 / 0$ & $0 / 1$ \\
\hline Bégin et al, 1987 (4) & $1(1 / 0)$ & 40 & $0 / 1$ & N/A \\
\hline
\end{tabular}

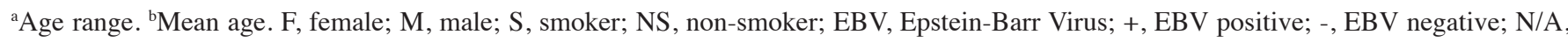
data not available.

immunohistochemical analyses confirmed the diagnosis of pulmonary LELC. The patient was healthy and asymptomatic following surgery. Thoracic enhancement CT revealed no signs of metastasis at three, six and 23 months following surgery.

\section{Discussion}

A network database search of PubMed and Web of Science was conducted using the keywords "pulmonary" and "LELC" for studies reported in the English language between 1987 and 2015. A total of 196 such cases (male, 96; female, 100) were described in the literature (Table I), and patient age ranged between 8 and 83 years. Among the 196 patients, 111 were smokers $(56.63 \%)$ and 45 were non-smokers $(22.96 \%)$, however, information regarding smoking status was unavailable for
$40(20.41 \%)$ patients. The first pulmonary LELC case was described by Bégin et al in 1987 (4). Of the 196 cases reported, the majority of cases involved Asian patients, with approximately two-thirds of cases arising in southern China $(12,40)$, Taiwan (11) and Hong Kong (29), illustrating the geographical distribution characteristics of pulmonary LELC. A close association exists between pulmonary LELCs and EBV infection, which is absent in other types of lung carcinomas. Among the 196 patients reported in the literature (Table I), 145 patients $(73.98 \%)$ tested positive for EBV infection, 42 patients $(21.43 \%)$ patients tested negative for EBV infection and information was unavailable for nine patients (4.59\%). Previous studies have identified the presence of EBV infection in the tumor cells or serum of LELC patients $(19,26,41)$. Circulating serum EBV DNA may be used as a tumor marker in the clinical management of patients with lung $\operatorname{LELC}(9,11,40,42)$. 
A study demonstrated that patients with a pretherapy serum EBV DNA level of $>10,000$ copies/ml exhibited significantly lower overall survival rates (18). Accurate diagnosis is significant and a prerequisite for treatment.

The diagnosis of lung LELC is usually based on the results of cytopathologic, histopathologic, immunohistochemical and EBER-positivity analyses, as well as a detailed systemic examination to exclude a possible extrapulmonary (nasopharyngeal) origin of the carcinoma and other lung diseases (43). Imaging diagnostic methods, including CT or magnetic resonance imaging (MRI) scans, are able to identify nonspecific lesions that resemble other pulmonary carcinomas. On CT scans, pulmonary LELCs usually appear as large, central, well-defined and lobulated tumors with vascular or bronchial encasement and obstructive pneumonia (43). Calcification has been rarely observed in pulmonary LELCs. In addition, MRI scans of LELCs usually detect an isointense or low-intensity signal on T1-weighted images and a slightly increased signal on T2-weighted images, while enhancement of abnormal tissue is typically observed $(19,44)$. The cytological features of the specimens are commonly analyzed by needle aspiration or fibrobronchoscopic brushing, which reveal abnormal cell morphology that usually appears as large clusters of neoplastic cells with scant cytoplasm. The nuclei are normally large and hyperchromatic, with irregular contour and prominent nucleoli (20). Histologically, the tumors appear solid and off-white in color, with a clear demarcation between the surrounding normal pulmonary tissues, while occasionally pleural invasion is observed. Immunohistochemical analysis of pulmonary LELCs usually detects positive staining of membrane tumor markers, including latent membrane protein-1, viral capsid antigen and CKs (20). In addition, EBER detection is significant in the diagnosis of pulmonary LELCs, since EBER is absent in other lung carcinomas, such as non-small-cell lung carcinomas. Similar to nasopharyngeal carcinomas, pulmonary LELCs are sensitive to chemotherapy and radiotherapy $(13,31)$. In early-stage pulmonary LELCs, the main treatment method is surgical resection, while comprehensive treatment (surgery, chemotherapy and radiotherapy) is adopted in patients with advanced or unresectable tumors (31). Previous studies have revealed that early-stage pulmonary LELC cases present an improved prognosis compared with advanced cases or other pulmonary carcinoma types in follow-ups after surgery $(10,16)$.

Fibrobronchoscopic brushing is the most widely used method with a decisive role in the diagnosis of lung carcinomas. In the present study, fibrobronchoscopic brushing revealed squamous metaplasia with severe hyperplasia at the middle lobe of the right lung. However, immunohistochemical analysis diagnosed the presence of a pulmonary LELC. Squamous metaplasia, which is the basis of squamous cell carcinomas, differs from pulmonary LELC in the therapeutic methods used and the prognostic evaluation. Squamous metaplasia requires regular follow-up in out-patient clinics, while pulmonary LELC is treated by surgery and chemotherapy. Therefore, distinguishing between LELC and other nonmalignant or premalignant conditions is essential. The present study indicated that despite the rarity of pulmonary LELC, it should be included as one of the differential diagnoses for lung malignancies. Therefore, physicians must consider performing larger biopsies, particularly when histological examination of tissue removed during surgery remains unidentified.

\section{Acknowledgements}

The authors would like to thank the staff of the Department of Thoracic Surgery at West-China Hospital of Sichuan University for their assistance and efforts.

\section{References}

1. Chow TL, Chow TK, Lui YH, et al: Lymphoepithelioma-like carcinoma of oral cavity: report of three cases and literature review. Int J Oral Maxillofac Surg 31: 212-218, 2002.

2. Ferrara G and Nappi O: Lymphoepithelioma-like carcinoma of the lung. Two cases diagnosed in Caucasian patients. Tumori 81: 144-147, 1995.

3. Chan JK, Hui PK, Tsang WY, et al: Primary lymphoepithelioma-like carcinoma of the lung. A clinicopathologic study of 11 cases. Cancer 76: 413-422, 1995.

4. Bégin LR, Eskandari J, Joncas J and Panasci L: Epstein-Barr virus related lymphoepithelioma-like carcinoma of lung. J Surg Oncol 36: 280-283, 1987.

5. AokiR,MitsuiH,Harada K,etal:Acaseoflymphoepithelioma-like carcinoma of the skin associated with Epstein-Barr virus infection. J Am Acad Dermatol 62: 681-684, 2010.

6. Yoshino T, Ohara S and Moriyama H: Lymphoepithelioma-like carcinoma of the urinary bladder: a case report and review of the literature. BMC Res Notes 7: 779, 2014.

7. Abdou AG and Asaad NY: Lymphoepithelioma-like carcinoma of the breast: Cytological, histological, and immunohistochemical characteristics. Diagn Cytopathol: Mar 8, 2014 (Epub ahead of print)

8. Bai Y, Gao Q, Ren G, et al: Epstein-Barr virus-associated lymphoepithelioma-like gastric carcinoma located on gastric high body: two case reports. Indian J Pathol Microbiol 57: 463-466, 2014.

9. Higashiyama M, DoiO,Kodama K, et al: Lymphoepithelioma-like carcinoma of the lung: analysis of two cases for Epstein-Barr virus infection. Hum Pathol 26: 1278-1282, 1995.

10. Huang CJ, Feng AC, Fang YF, et al: Multimodality treatment and long-term follow-up of the primary pulmonary lymphoepithelioma-like carcinoma. Clin Lung Cancer 13: 359-362, 2012.

11. Chang YL, Wu CT, Shih JY and Lee YC: New aspects in clinicopathologic and oncogene studies of 23 pulmonary lymphoepithelioma-like carcinomas. Am J Surg Pathol 26: 715-723, 2002.

12. Han AJ, Xiong M, Gu YY, et al: Lymphoepithelioma-like carcinoma of the lung with a better prognosis. A clinicopathologic study of 32 cases. Am J Clin Pathol 115: 841-850, 2001.

13. Ho JC, Wong MP and Lam WK: Lymphoepithelioma-like carcinoma of the lung. Respirology 11: 539-545, 2006.

14. Chen FF, Yan JJ, Lai WW, et al: Epstein-Barr virus-associated nonsmall cell lung carcinoma: undifferentiated "lymphoepithelioma-like" carcinoma as a distinct entity with better prognosis. Cancer 82: 2334-2342, 1998.

15. Curcio LD, Cohen JS, Grannis FW Jr, et al: Primary lymphoepithelioma-like carcinoma of the lung in a child. Report of an Epstein-Barr virus-related neoplasm. Chest 111: 250-251, 1997.

16. Liang Y, Wang L, Zhu Y, et al: Primary pulmonary lymphoepithelioma-like carcinoma: fifty-two patients with long-term follow-up. Cancer 118: 4748-4758, 2012.

17. Bolgova LS, Gordienko TM, Mantsurov NE, et al: Exfoliative cytological diagnosis of lung cancer with bronchoscopic material. Klin Lab Diagn: 15-17, 2009 (In Russian).

18. Ngan RK, Yip TT, Cheng WW, et al: Clinical role of circulating Epstein-Barr virus DNA as a tumor marker in lymphoepithelioma-like carcinoma of the lung. Ann N Y Acad Sci 1022: 263-270, 2004.

19. MaH,Wu Y,Lin Y,CaiQ,Ma Gand Liang Y: Computed tomography characteristics of primary pulmonary lymphoepithelioma-like carcinoma in 41 patients. Eur J Radiol 82: 1343-1346, 2013.

20. Hayashi T, Haba R, Tanizawa J, et al: Cytopathologic features and differential diagnostic considerations of primary lymphoepithelioma-like carcinoma of the lung. Diagn Cytopathol 40: 820-825, 2012. 
21. Jeong JS, Kim SR, Park SY, et al: A Case of Primary Pulmonary Lymphoepithelioma-like Carcinoma Misdiagnosed as Adenocarcinoma. Tuberc Respir Dis (Seoul) 75: 170-173, 2013.

22. Dong A, Zhang J, Wang Y, et al: FDG PET/CT in Primary Pulmonary Lymphoepithelioma-like Carcinoma. Clin Nucl Med 40: 134-137, 2015.

23. Yener NA, Balikçi A, Çubuk R, et al: Primary lymphoepithelioma-like carcinoma of the lung: report of a rare case and review of the literature. Turk Patoloji Derg 28: 286-289, 2012.

24. Tanaka S, Chen F and Date H: Pulmonary lymphoepitheliomalike carcinoma with rapid progression. Gen Thorac Cardiovasc Surg 60: 164-167, 2012.

25. Shen DH, Cheng CY, Lin LF, et al: Conversion from FDG-negative to -positive during follow-up in a rare case of pulmonary lymphoepithelioma-like carcinoma. Clin Nucl Med 37: 679-681, 2012.

26. Xia J, Jiang L, Zhang J, et al: The Clinical Analysis of 21 Patients with Lymphoepithelioma-like Carcinoma after Operation. Zhongguo Fei Ai Za Zhi 12: 1169-1173, 2009 (In Chinese).

27. Bildirici K, Ak G, Peker B, et al: Primary lymphoepithelioma-like carcinoma of the lung. Tuberk Toraks 53: 69-73, 2005.

28. Kobayashi M, Ito M, Sano K, et al: Pulmonary lymphoepitheliomalike carcinoma: predominant infiltration of tumor-associated cytotoxic T lymphocytes might represent the enhanced tumor immunity. Intern Med 43: 323-326, 2004.

29. Ho JC, Lam WK, Wong MP, et al: Lymphoepithelioma-like carcinoma of the lung: experience with ten cases. Int J Tuberc Lung Dis 8: 890-895, 2004.

30. Hernández Vázquez J, de Miguel Díez J, Llorente Iñigo D, et al: Large cell lymphoepithelioma-like carcinoma of the lung. Arch Bronconeumol 40: 381-383, 2004 (In Spanish).

31. Abe T, Tanabe Y, Watanabe S, et al: A case of recurrent pulmonary lymphoepithelioma-like carcinoma responding to treatment with CBDCA/paclitaxel combined chemotherapy. Gan To Kagaku Ryoho 31: 1215-1217, 2004 (In Japanese).

32. Morbini P, Riboni R, Tomaselli S, et al: Eber- and LMP-1-expressing pulmonary lymphoepithelioma-like carcinoma in a Caucasian patient. Hum Pathol 34: 623-625, 2003.

33. Barroso A, Nogueira R, Lencastre H, et al: Primary lymphoepithelioma-like carcinoma of the lung. Lung Cancer 28: 69-74, 2000.
34. Kasai K, Kon S, Sato N, et al: Case report of lymphoepitheliomalike carcinoma of the lung - lymphoid population consisting of cytotoxic T cells in resting state. Pathol Res Pract 195: 773-779, 1999.

35. Wöckel W, Höfler G, Popper HH and Morresi-Hauf A: Lymphoepithelioma-like lung carcinomas. Pathologe 18: 147-152, 1997 (In German).

36. Wong MP, Chung LP, Yuen ST, et al: In situ detection of Epstein-Barr virus in non-small cell lung carcinomas. J Pathol 177: 233-240, 1995.

37. Wöckel W, Höfler G, Popper HH and Morresi A: Lymphoepithelioma-like carcinoma of the lung. Pathol Res Pract 191: 1170-1174, 1995.

38. Chow LT, Chow WH, Tsui WM, et al: Fine-needle aspiration cytologic diagnosis of lymphoepithelioma-like carcinoma of the lung. Report of two cases with immunohistochemical study. Am J Clin Pathol 103: 35-40, 1995.

39. Miller B, Montgomery C, Watne AL, et al: Lymphoepithelioma-like carcinoma of the lung. J Surg Oncol 48: 62-68, 1991.

40. Han AJ, Xiong M and Zong YS: Association of Epstein-Barr virus with lymphoepithelioma-like carcinoma of the lung in southern China. Am J Clin Pathol 114: 220-226, 2000.

41. Hsu JL and Glaser SL: Epstein-barr virus-associated malignancies: epidemiologic patterns and etiologic implications. Crit Rev Oncol Hematol 34: 27-53, 2000.

42. Han A, Xiong M and Zong Y: Association of epstein-barr virus with lymphoepithelioma-like carcinoma of the lung. Zhonghua Bing Li Xue Za Zhi 26: 222-224, 1997 (In Chinese).

43. Mo Y, Shen J, Zhang Y, et al: Primary lymphoepithelioma-like carcinoma of the lung: distinct computed tomography features and associated clinical outcomes. J Thorac Imaging 29: 246-251, 2014.

44. HoxworthJM,HanksDK,AraozPA,etal:Lymphoepithelioma-like carcinoma of the lung: radiologic features of an uncommon primary pulmonary neoplasm. AJR Am J Roentgenol 186: 1294$1299,2006$. 